\title{
Pour en lire plus : 30 ans au RQGE - Une histoire dissidente du mouvement écologiste au Québec
}

Lucie Sauvé

\section{(2) OpenEdition \\ Journals}

Édition électronique

URL : http://journals.openedition.org/ere/852

DOI : $10.4000 /$ ere.852

ISSN : 2561-2271

Éditeur

Centr'ERE

Référence électronique

Lucie Sauvé, "Pour en lire plus : 30 ans au RQGE - Une histoire dissidente du mouvement écologiste au Québec », Éducation relative à l'environnement [En ligne], Volume 11 | 2014, mis en ligne le 20 décembre 2013, consulté le 24 septembre 2020. URL : http://journals.openedition.org/ere/852 ; DOI : https://doi.org/10.4000/ere.852 


\section{Pour en lire plus : 30 ans au RQGE - Une histoire dissidente du mouvement écologiste au Québec}

Lucie Sauvé

\section{RÉFÉRENCE}

Philippe Saint-Hilaire Gravel (2012). 30 ans au RQGE - Une histoire dissidente du mouvement écologiste au Québec. Montréal : Réseau québécois des groupes écologistes

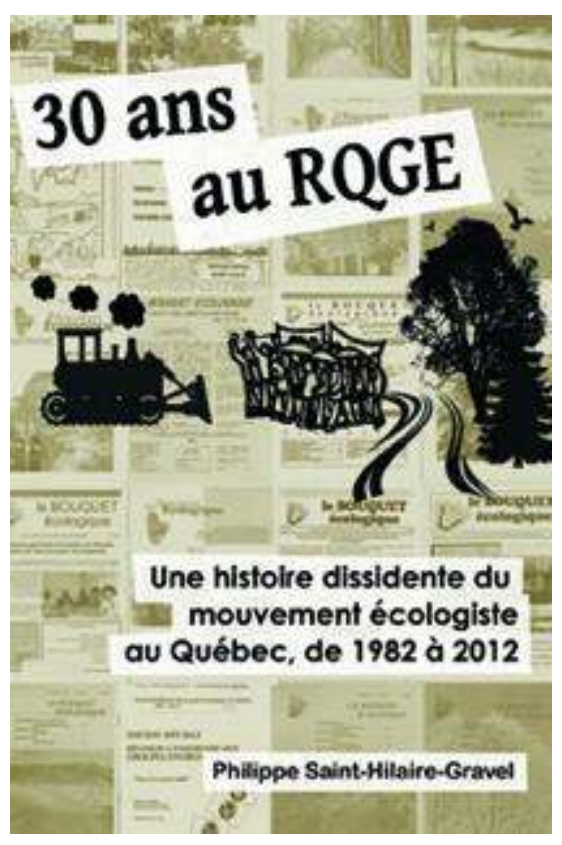


1 À travers cette chronique du RQGE depuis sa fondation en 1982, Philippe Saint-Hilaire Gravel présente de larges pans de l'histoire environnementale du Québec. Je me souviens... des dynamiques politiques, des mouvements de résistance, des luttes qui se répètent et se ressemblent. Celle contre le nucléaire par exemple. Cette riche histoire d'engagement, exaltante et courageuse, souvent douloureuse, il importe de la raviver parce qu'elle

2 permet de célébrer l'engagement remarquable de ses acteurs et offre une meilleure compréhension des situations actuelles. La trajectoire du RQGE, inscrite dans la mouvance des dernières décennies, fait partie du patrimoine social et écologique du Québec. En cette époque d'effervescence au sein de la société québécoise, cet ouvrage éclairant doit être lu en particulier par les nouveaux acteurs des revendications écosociales: ils y saisiront mieux le paysage évolutif dans lequel ils inscrivent leur action collective; ils y trouveront des clés d'explication et des pistes pour mieux appréhender les enjeux de leur militance. Cette chronique saura rejoindre également les anciens compagnons de route ou de débats, qui pourront y porter leur propre regard et contribuer à l'enrichir, à la mettre en relief ou en contraste avec leur propre analyse.

3 L'histoire du RQGE évolue au cœur d'une double tension, celle qui oppose les deux «âmes de l'écologie » selon l'expression de Romain Felli (2008) : d'une part l'écologie politique et d'autre part le développement durable. D'une part, la critique écologiste qui dénonce les racines des déséquilibres sociaux et environnementaux, étroitement liés entre eux, et propose des transformations profondes vers une écosociété. D'autre part, le projet du développement durable qui tente de concilier économie et environnement et d'« intégrer la contestation écologique pour la mettre au service de la production des conditions de production" (Felli, 2008, p. 89). Le RQGE, témoin et acteur de l'évolution de la pensée écologiste et des politiques environnementales au Québec, a vite saisi les limites de l'approche managériale du développement durable et les dérives qu'elle entraîne. L'ouvrage de Philippe Saint-Hilaire-Gravel explicite bien la rupture qu'a introduite une telle approche au sein du mouvement écologiste. Il met en évidence le remarquable souci d'authenticité et d'intégrité des acteurs du RQGE dans leurs luttes avec ou malgré les autres acteurs de la scène environnementale, en dissension avec ceux qu'ils appellent les "professionnels de l'environnement", partenaires du pouvoir politico-économique.

4 Comment qualifie-t-on maintenant un développement de "vert»? Pour beaucoup, prononcer ces mots laisse un goût amer dans la bouche (...) Entre l'écologie sociale et la critique des habitudes personnelles des " consom-mateurs ", qui laisse intact le pouvoir fabuleux des entreprises à contrôler le développement économique, il y a un gouffre. (Saint-Hilaire-Gravel, p.198)

5 Plus récemment, l'inscription du RQGE dans le mouvement de l'«action communautaire autonome " élargit sa mission, manifestant un souci de décloisonner les luttes écologistes et de les rapprocher des luttes sociales. Des liens se créent entre l'écologie politique et l'économie sociale à travers la promotion des initiatives locales, autonomes et démocratiques, axées sur les principes d'équité sociale et de justice écologique. Philippe Saint-Hilaire-Gravel raconte comment le RQGE aborde les questions de l'eau, de l'énergie, des forêts, du transport, de la biodiversité, de la santé environnementale, de la consommation... du local au global et dans une perspective socio-écologique. Des liens avec les organisations de femmes, d'autochtones, de jeunes 
se tissent. Dénonçant les situations de précarité, d'oppression et d'iniquité, le RQGE associe ses luttes écologistes à la « défense du droit d'exister pour les groupes locaux et citoyens ».

6 L'histoire du RQGE est un hommage à l'intégrité de la critique écologiste et à l'engagement de ses acteurs. La lecture de cet ouvrage s'impose pour quiconque s'engage dans la mouvance socio-écologique actuelle au Québec et aussi pour tous les artisans de la culture écologiste (dont les éducateurs!) et les pionniers de l'action environnementale qui ont contribué à forger notre société. Ils y trouveront le souffle de la mémoire, l'élan de l'inspiration et peut-être, de nouveaux lieux de débats.

\section{BIBLIOGRAPHIE}

Felli, R. (2008). Les deux âmes de l'écologie - Une critique du développement durable. Paris :

L'Harmattan.

\section{AUTEUR}

\section{LUCIE SAUVÉ}

Directrice du Centre de recherche en éducation et formation relatives à l'environnement et à

l'écocitoyenneté Université du Québec à Montréal 